\title{
Clinical Approach to Sodium Homeostasis Disorders in Children with Pituitary-Suprasellar Tumors
}

\author{
Gerdi Tulia,b Patrizia Matarazzo ${ }^{a, b}$ Luisa de Sanctis ${ }^{a, b}$ \\ ${ }^{a}$ Department of Pediatric Endocrinology, Regina Margherita Children's Hospital, City of Health and Science \\ University Hospital of Turin, Turin, Italy; ${ }^{\mathrm{b}}$ Department of Public Health and Pediatric Sciences, University of Turin, \\ Turin, Italy
}

\section{Keywords}

Hyponatremia $\cdot$ Hypernatremia $\cdot$ Pituitary tumors $\cdot$ Children

\begin{abstract}
Children with pituitary-suprasellar tumors are at high risk of developing sodium metabolism disorders since the tumoral mass itself or surgical and medical treatment can damage AVP release circuits. Additional risk factors are represented by the use of hypotonic fluids, the young age, total parenteral nutrition, and obstructive hydrocephalus secondary to tumor pathology. The most frequent hyponatremic disorders related to AVP in these patients are the syndrome of inappropriate $A D H$ secretion and the cerebral/renal salt wasting syndrome, while hypernatremic conditions include central diabetes insipidus (CDI) and adipsic CDI. The main challenge in the management of these patients is to promptly distinguish the AVP release disorder at the base of the sodium imbalance and treat it correctly by avoiding rapid sodium fluctuations. These disorders can coexist or follow each other in a few hours or days; therefore, careful clinical and biochemical monitoring is necessary, especially during surgery, the use of chemotherapeutic agents, or radiotherapy. This monitoring should be performed by experienced healthcare professionals and should be multidisciplinary, including pediatric endocrinologists, neurosurgeons, and
\end{abstract}

(c) 2019 S. Karger AG, Basel oncologists since maintaining sodium homeostasis also plays a prognostic role in terms of disease survival, therapeutic response, hospitalization rate, and mortality. In this review, we analyze the management of sodium homeostasis disorders in children with pituitary-suprasellar tumors and discuss the main challenges in the diagnosis and treatment of these conditions based on literature data and over 30 years of clinical experience at our Department of Pediatric Endocrinology.

(c) 2019 S. Karger AG, Basel

\section{Introduction}

The sodium and water balance is regulated by many hormonal and neuronal circuits that cooperate for the maintenance of serum sodium and osmolality within the normal ranges [1-7]. This strict regulation explains the fact that imbalance of sodium homeostasis is the most common electrolyte alteration in hospitalized children $[8,9]$. Sodium is the main electrolyte in extracellular fluids, and it is fundamental for the well-being of many tissues, especially for neurons and for growth plate cartilage; its derangements influence neuro-psychomotor development and growth in very young patients [10-13]. Rapid fluctuations in serum sodium lev-

\section{KARGER}

E-Mail karger@karger.com

www.karger.com/nen
Dr. Gerdi Tuli

Department of Pediatric Endocrinology

Regina Margherita Children's Hospital

Piazza Polonia 94, IT-10126 Turin (Italy)

E-Mail gtuli@unito.it 
els are associated with symptoms that vary depending on the severity of the hypo- or hypernatremia, ranging from asymptomatic states to failure to thrive, anorexia, nausea, vomiting, headache, seizures, irritability, confusion, hallucinations, seizures, coma, and even death. In patients with hypothalamic-pituitary lesions, the cerebral tumor mass damages the neuroanatomical circuits of AVP release and exposes these children to disorders of sodium metabolism in a higher ratio than pediatric patients with blood tumors, solid non-brain solid tumors, or also other cerebral tumors that do not affect the pituitary region (e.g., medulloblastoma or ependymo$\mathrm{ma})$. On the other hand, the medical/surgical treatment of hypothalamic-pituitary tumors increases the risk of developing sodium metabolism disorders influencing AVP release. The most frequent tumor masses in the pituitary-suprasellar region are craniopharyngioma (5$15 \%)$, ganglioglioma (10-18\%), and germinoma (3\%), which represent about $19 \%$ of all brain tumors in childhood, while pituitary adenomas are uncommon at this age [13-19]. Pediatric patients with these types of tumors are at high risk of hyponatremia and hypernatremia at any time, before the tumor is diagnosed, during and after neurosurgery, during chemotherapy or radiotherapy and in case of recurrence of the disease [14-20]. The main risk factors are age-related, that is, the younger the patient, the more frequent and severe the hyponatremia or hypernatremia, but also linked to the tumor site, more frequent in case of pituitary and stalk involvement, to neurosurgery of the pituitary or of the suprasellar area, to the neuroanatomical integrity of the thirst circuits, to the type of chemotherapy drugs, if vincristine, cyclophosphamide, carbamazepine, opioids, methotrexate, and even to the hypotonic fluids usually prescribed during chemotherapy and radiotherapy. Moreover, the often associated nausea promotes the secretion of AVP, leading to a hyponatremic state further worsened by the vomiting. Obstructive hydrocephalus and total parenteral nutrition are other risk factors that can contribute to the development of an imbalance of sodium metabolism [21-31].

In children with parasellar tumors, the syndrome of inappropriate $\mathrm{ADH}$ secretion (SIADH) and the cerebral/ renal salt wasting syndrome (C/RSW) represent the most frequent hyponatremic disorders [32-40], while central diabetes insipidus (CDI) and the adipsic CDI are the main hypernatremic ones [14, 20, 41-51]. These conditions can coexist in the same patient or follow each other in a few hours or days, so close clinical and biochemical monitoring is mandatory [52-61].
These conditions can be acute or chronic, transient, or persistent and may be associated with any hormonal deficiency of the anterior pituitary (ACTH, TSH, GH, or LH/FSH deficiency), hypothalamic obesity, or more rarely a precocious puberty, gonadotropin-dependent or induced by $\beta$-human chorionic gonadotropin secretion.

Because hyponatremia and hypernatremia can be associated with severe neurological symptoms and cellular damage, timely diagnosis and treatment are essential to avoid related sequelae. Recent literature data indicate that the maintenance of sodium homeostasis has a prognostic role in terms of disease survival, therapeutic response, hospitalization rate, and even mortality [10-13].

A novelty in the diagnosis of sodium imbalances is the introduction of the copeptin measurement, an AVP surrogate, secreted in an equimolar way, especially useful in the case of hyponatremia.

Similarly, as regards the treatment of pituitary tumors and endocrine sequelae, a great improvement over the years is linked to the greater knowledge of neuroanatomical structures and to their rescue during surgery, to the revision of chemotherapeutic protocols, to the use of new radiotherapeutic strategies with proton beams, to the replacement of hypotonic infusions with isotonic fluids as maintenance liquids during chemotherapy, and to the introduction of new classes of drugs, such as vaptans, in the treatment of chronic SIADH.

However, sodium metabolism disorders are still common in these patients, and management is still challenging with the need for a multidisciplinary approach that includes pediatric endocrinologists, neurosurgeons, and oncologists.

The purpose of this paper is to review the diagnostic and therapeutic management of sodium homeostasis disorders in children affected by pituitary-suprasellar tumors, based on literature data and over 30 years of clinical experience in our Pediatric Endocrinology Department in which we took care of over 100 patients with pituitarysuprasellar tumors, of which 21 with germinomas, 43 with craniopharyngiomas, and 41 with astrocytomas, almost all experiencing derangements of sodium metabolism during the follow-up period.

\section{Hyponatremia Clinical Management}

\section{Definition}

Hyponatremia is defined by serum sodium levels below $135 \mathrm{mmol} / \mathrm{L}$; it can occur in case of sodium net loss or volume overload. In relation to the volemic state, hyponatremia may be euvolemic, hypovolemic, or hyper- 


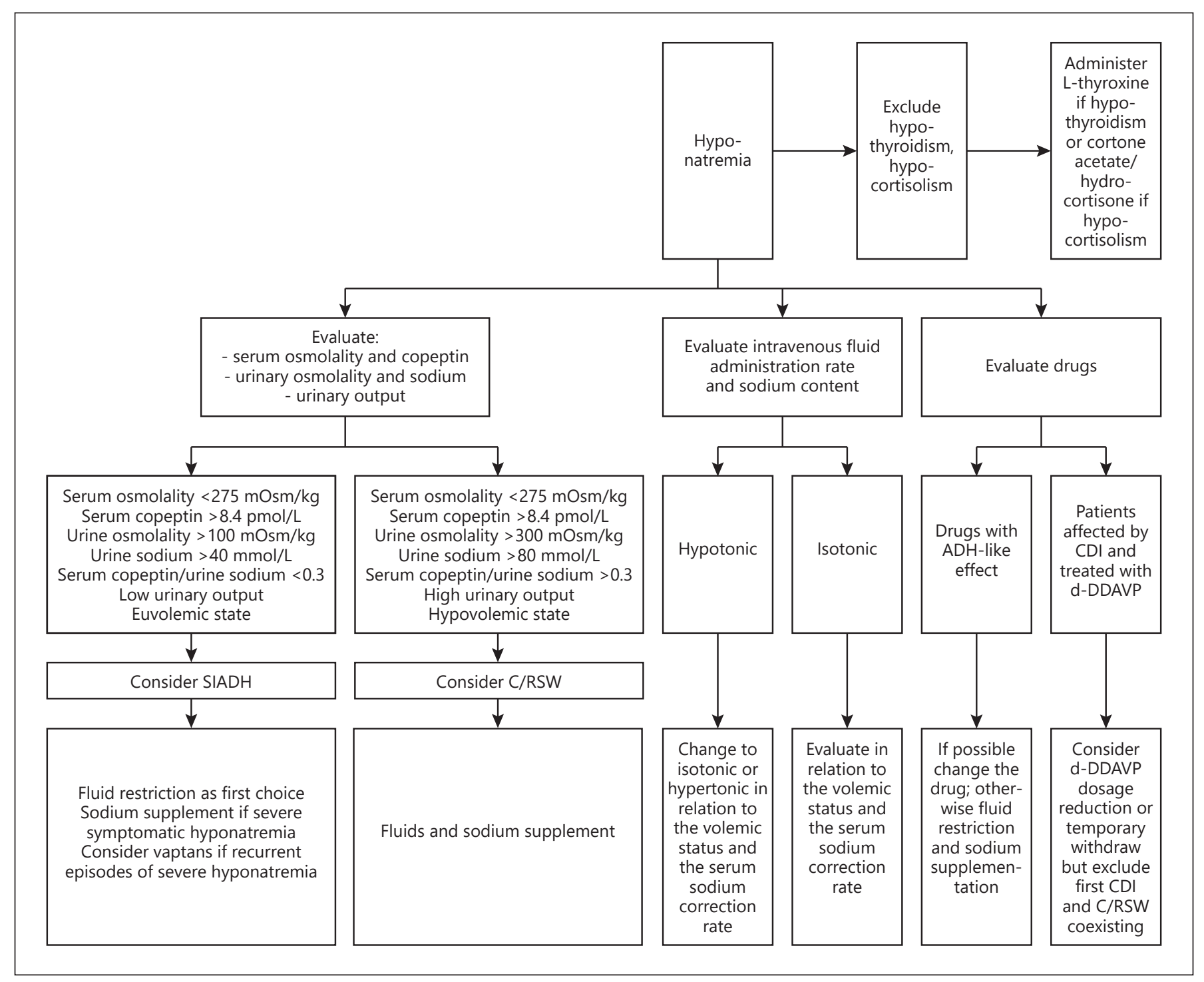

Fig. 1. The clinical management of hyponatremia.

volemic, whereas by considering the severity it can be classified as mild (134-130 mmol/L), moderate (129-124 $\mathrm{mmol} / \mathrm{L})$, and severe $(<124 \mathrm{mmol} / \mathrm{L})$.

\section{Clinical and Biochemical Evaluation}

The clinical management of hyponatremia is represented in Figure 1.

In front of a condition of hyponatremia, the urinary production and the sodium content of intravenous fluids possibly administered, as well as the quantities of liquids orally ingested, must be precisely quantified; any drug that interferes with serum sodium levels should also be considered. At first, in the presence of hyponatremia the evaluation of the thyroid and adrenal function is of primary importance to exclude hypothyroidism or hypocortisolism, a frequent cause of hyponatremia, and, if present, must be corrected. Further biochemical evaluations should include blood counts, serum potassium, creatinine, urea, osmolality and copeptin values, urine density and osmolality, and sodium excretion.

\section{Clinical Management of the Main Hyponatremic Conditions}

Hypothyroidism or Hypocortisolism

Primary or secondary hypothyroidism or hypocortisolism may occur in patients affected by brain tumors due 
to hypothalamic/pituitary surgical or radiation injury or chemotherapy agents [52, 62-65]. Radiation doses above $20 \mathrm{~Gy}$ are related to the development of central hypothyroidism; when the dose is above 30 Gy the risk is higher for both central and primary hypothyroidism. The use of chemotherapeutic agents such as lomustine, bleomycin, and cyclophosphamide has also been related to the hypothalamic-pituitary-thyroid axis (HPTA), although the estimated risk attributable to chemotherapy is much lower than that for radiotherapy, which is inversely associated with age at exposure. Compared to other pituitary hormone axes, the dysfunction of the hypothalamic-pituitary-adrenal axis (HPAA) is more resistant to cranial irradiation, but in case of an irradiating dose above $30 \mathrm{~Gy}$, the risk of injury increases. In the absence of intracranial or total body irradiation, chemotherapy-related HPAA dysfunction is uncommon. Adrenal insufficiency related to chemotherapy may be present in acute treatment, but the evidence of its long-term effects is minimal. Iatrogenic adrenal insufficiency is common in children with brain tumors after prolonged high doses of glucocorticoid therapy and may persist for some time even if treatment is gradually discontinued. Therefore, thyroid and adrenal function has to be evaluated periodically, generally every year, and in the case of indicative symptoms, such as fatigue, reduced resistance, poor weight gain, which however are very nonspecific and common in children with cancer, and in the case of hyponatremia or hypoglycemia. Evaluation of thyroid function includes TSH, fT4, fT3 dosage, titration of anti-thyroid-peroxidase and thyroglobulin antibodies, and ultrasound control of the thyroid gland. The biochemical investigation of HPAA is more difficult to assess because morning cortisol and ACTH evaluation or cortisol profile may not be sufficient at all, and dynamic tests such as the ACTH test with low dose $(1 \mu$ g i.v. $)$ or standard dose $(250 \mu$ i.v. $)$ and an insulin tolerance test may be required. In case of HPTA or HPAA, replacement treatment should be started as soon as possible with L-thyroxine $(1-4 \mu \mathrm{g} / \mathrm{kg} /$ day $)$ and/or hydrocortisone $\left(10 \mathrm{mg} / \mathrm{m}^{2} /\right.$ day $)[62,63]$.

\section{Syndrome of Inappropriate ADH Secretion}

SIADH is a condition of euvolemic hyponatremia [66]. The typical presentation includes hyponatremia $(<135 \mathrm{mmol} / \mathrm{L})$, low serum osmolality $(<275 \mathrm{mOsm} / \mathrm{kg})$, inappropriately high urine osmolality ( $>100 \mathrm{mOsm} / \mathrm{kg})$, and euvolemia with contraction of diuresis and lowered osmotic threshold for thirst. Usually, there are no symptoms of water retention, since normally only a third of the body water content is found in the extracellular compart- ment. SIADH is mainly a chronic condition, but in oncologic patients it is often an acute and dramatic event, difficult to manage.

The treatment of chronic hyponatremia due to SI$\mathrm{ADH}$ requires fluid restriction $(20 \mathrm{~mL} / \mathrm{kg} / 24 \mathrm{~h}$ or about $500 \mathrm{~mL}$ less than daily urinary output), while the treatment of acute and severe symptomatic hyponatremia may require intravenous sodium supplementation through iso-hypertonic solutions [66-77]. Obtaining or maintaining fluid restriction is often a challenge due to the poor compliance of these subjects who have a lower thirst threshold [75]. In our experience, the restriction of fluids is often difficult to obtain even for the concomitant use of other therapeutic agents, such as antibiotics or chemotherapy drugs needing larger amounts of fluids, or due to the high proportion of fluids administrated to preserve kidney function. In these cases, oral sodium supplementation (1-2 g/day) may also be necessary. When the underlying disease responsible for the SIADH is a chronic condition, that is, linked to a large tumor mass in the suprasellar region, chronic hyponatremia can occur, with potential severe neurological symptoms such as seizures and consciousness alteration. This complication can drive the decision to use a class of drugs called vaptans, aquaretic agents capable of inducing polyuria [7882]. For this treatment, children must be hospitalized, and they must start with low-dose titration; subsequently, the dosage should be modulated by monitoring serum sodium levels and urine output for at least $48-72 \mathrm{~h}$. To avoid a rapid fluctuation of the serum sodium level, patients can have free access to water during this therapeutic regimen, but they must be strictly monitored for changes in sodium and osmolality, and the previous treatments of hyponatremia must be progressively withdrawn.

Usually, serum sodium normalizes in $24-48 \mathrm{~h}$, while urinary output stabilizes in 15-20 days, due to the electrolyte-free aquaresis caused by tolvaptan. However, so far few studies have been published on the use of tolvap$\tan$ in pediatric age and for patients under the age of 18 , both in Europe and in the USA, and today it is still considered an off-label drug. Although current data indicate good efficacy and safety, to reinforce these preliminary results on its use in euvolemic hyponatremia related to SIADH in children, further studies are needed [78-82].

\section{Cerebral/Renal Salt Wasting Syndrome}

The cerebral salt wasting (CSW) syndrome, more correctly defined as C/RSW, is an acute hypovolemic hyponatremic condition whose pathogenetic mechanism is 
Table 1. Main clinical and biochemical differences between SIADH and C/RSW

\begin{tabular}{llll}
\hline & SIADH & C/RSW & Reference \\
\hline Body weight & increased & stable or decreased & {$[13,83]$} \\
Arterial blood pressure & stable or increased & decreased & {$[13,83]$} \\
Dehydration & no & yes & {$[13,83]$} \\
Serum sodium & decreased & decreased & {$[13,83]$} \\
Urine sodium & increased & increased & {$[13,83]$} \\
Urine output & decreased & increased & {$[13,83]$} \\
Serum osmolality & decreased & decreased & {$[13,83]$} \\
Urine osmolality & increased & increased & {$[13,83]$} \\
Urine osmolality/ & $>1$ & $>1$ & {$[13,83]$} \\
serum osmolality & & & {$[13,83]$} \\
\hline Serum urea & decreased & normal/increased & {$[13,83]$} \\
Serum urate & decreased & increased & {$[13,83]$} \\
Hematocrit & necreased & normal/increased & {$[13,83]$, modified } \\
Serum ADH & increased & (but lower than in SIADH) & \\
Serum copeptin & first decreased and then increased & {$[13,83]$, modified } \\
Serum natriuretic peptide & increased & (but lower than in SIADH) & {$[13,83]$} \\
Serum copeptin/ & $<0.3$ & $>0.3$ & {$[84]$} \\
urinary sodium ratio & & & \\
\hline
\end{tabular}

still controversial. It seems to be related to a reduction of renal sympathetic stimulation, with a concomitant involvement also of natriuretic peptides in the brain, resulting in a suppression of renin, aldosterone, and AVP secretion [13, 35-39]; the final result is renal sodium resorption decrease, with consequent hypovolemic state.

In C/RSW, the hypovolemic stimulus is more effective on AVP secretion than the hypo-osmolar one; the subsequent compensatory AVP release is then responsible for the hyponatremic state despite the low serum osmolality. Typical features of this condition are hyponatremia, hypovolemia, and renal sodium loss resulting in an increase in urine output and high urine osmolality. In some cases, it is very challenging to distinguish C/RWS from SIADH, as the volemic state is the only marker that allows the definite diagnosis; hypovolemia is present in the C/RSW, whereas euvolemia is typical of the SIADH condition. The main clinical and biochemical features of SIADH and C/RSW are represented in Table 1.

The C/RSW treatment requires the integration of liquids and salt to support circulation and compensate for renal sodium loss $[13,15]$. The daily sodium supplement is shown in Table 2; the daily fluid requirement is higher than the norm, equal to $80-100 \mathrm{~mL} / \mathrm{kg} /$ day. When hyponatremia persists, fludrocortisone at $0.025-1 \mathrm{mg} /$ day can be used.

Sodium Disorders in Children with Pituitary-Suprasellar Tumors
Rapid correction of serum sodium must be avoided; the standard sodium correction over time should be 4-6 $\mathrm{mmol} / \mathrm{L}$ in the first $4-6 \mathrm{~h}, 10-12 \mathrm{mmol} / \mathrm{L}$ in the first $24 \mathrm{~h}$, $<18 \mathrm{mmol} / \mathrm{L}$ in the first $48 \mathrm{~h}$ [13].

\section{Hyponatremia Related to Hypotonic Fluids and Drugs}

To avoid the imbalance of sodium and water homeostasis and to promptly adjust the 1-deamino-8-D-arginine-vasopressin (d-DDAVP) dosage in CDI patients, during chemotherapy or radiotherapy, serum sodium and osmolality, urinary osmolality, and output must be carefully monitored.

The high rate of hypotonic fluid maintenance, the use of potential $\mathrm{ADH}$-like drugs, such as vincristine, vinblastine, ifosfamide, and cisplatin, and SIADH induced by nausea/vomiting are the main risk factors of development of hyponatremia during chemotherapy; the inflammatory state of the neuronal tissue and/or the change in the volume of the tumor mass can lead to C/RSW in exceptional cases during radiotherapy [65].

Indeed, during chemotherapy, large amounts of fluids are needed to preserve kidney function and avoid the toxicity of chemotherapy drugs; however, hypotonic fluids should be avoided in patients in pediatric age with brain tumors, especially when the neuroanatomical circuits of thirst and the release of AVP release are compromised. 


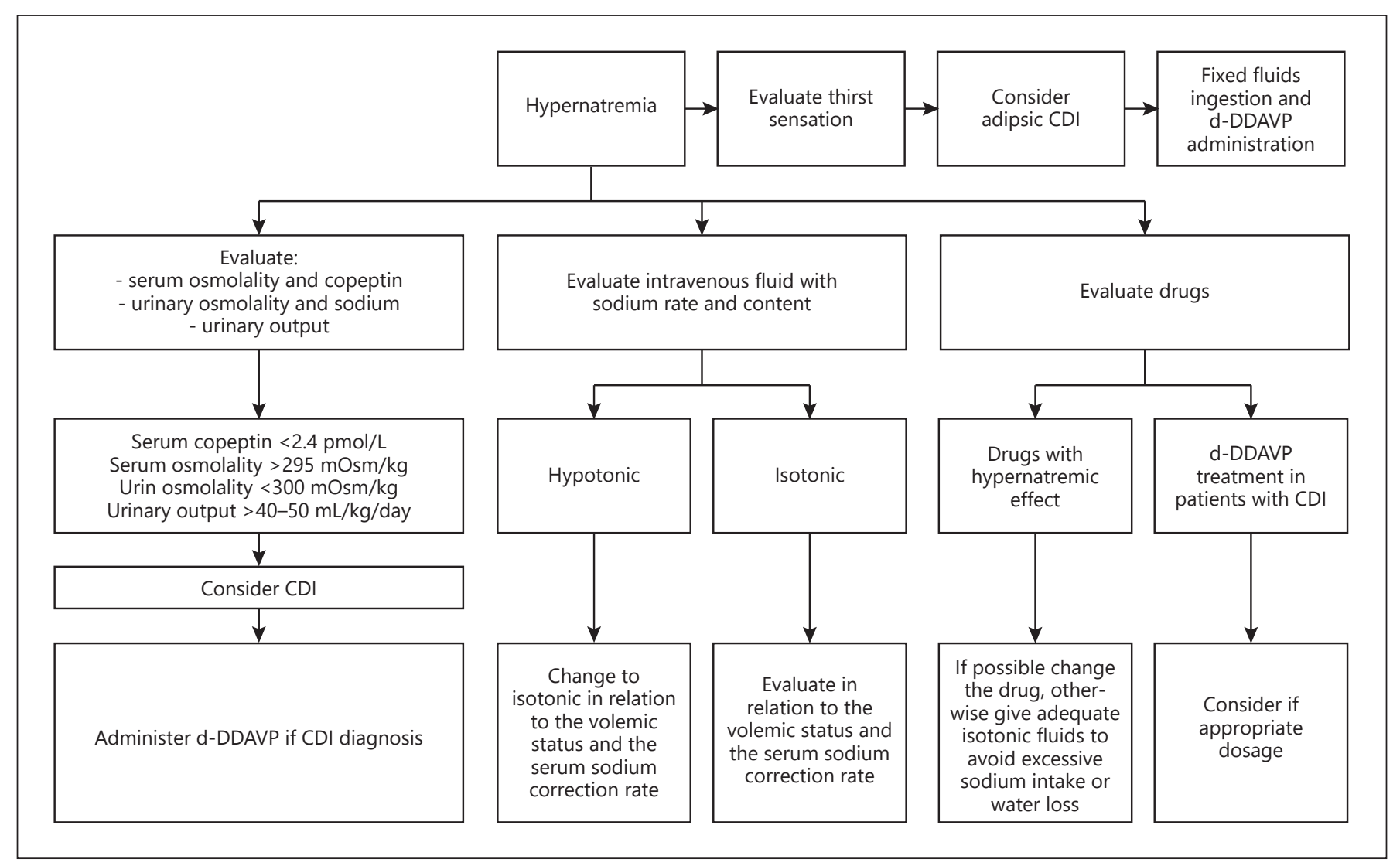

Fig. 2. The clinical management of hypernatremia.

Table 2. Daily sodium intake in relation to hyponatremia

\begin{tabular}{ll}
\hline Serum sodium & $\begin{array}{l}\text { Sodium daily administration, } \\
\mathrm{mmoL} / \mathrm{kg} / \text { day }\end{array}$ \\
\hline $130-135 \mathrm{mmol} / \mathrm{L}$ & $2-3$ \\
$124-130 \mathrm{mmol} / \mathrm{L}$ & $5-6$ \\
$<124 \mathrm{mmol} / \mathrm{L}$ & $6-10$ \\
\hline
\end{tabular}

From our own experience, also supported by data from the literature, in that situation the standard maintenance fluids are represented by isotonic solutions [83-88].

In patients with CDI and concomitant SIADH, fluid restriction is needed, and d-DDAVP dosage reduction or temporary withdrawal is indicated; in case of C/RSW, the main challenge is to interpret the worsening of polyuria, by differentiating between an insufficient d-DDAVP dosage from coexistence of the CDI and C/RSW conditions $[13,89]$. Low urine sodium and low urine osmolality should help in orienting towards a d-DDAVP dose in- crease; high urine sodium and high urine osmolality should drive the decision to administer fluids and sodium and eventually reduce the d-DDAVP dosage.

\section{Hypernatremia Clinical Management}

\section{Definition}

Hypernatremia is defined by serum sodium levels above $145 \mathrm{mmol} / \mathrm{L}$ and occurs in presence of sodium excess, pure water loss, or low fluid intake.

\section{Clinical and Biochemical Evaluation}

The clinical management of hypernatremia is represented in Figure 2. Urinary output and the sodium content of liquids possibly administered intravenously, as well as the amount of fluid ingested orally and the presence of a thirsty sensation must be precisely quantified. Any medication that interferes with serum sodium levels should also be considered. Further biochemical evaluation should include a serum sample for blood count, po- 
tassium, creatinine, urea, osmolality, and copeptin and a urine sample for density, osmolality, and sodium.

\section{Clinical Management of the Main Hypernatremic Conditions}

Central Diabetes Insipidus

$\mathrm{CDI}$ is clinically characterized by polyuria-polydipsia with extremely diluted urine excretion, inability to concentrate urine due to AVP deficiency, and consequent compensatory polydipsia [13, 44, 45, 51, 90-94]. When the compensatory mechanism of polydipsia fails, dehydration, vomiting, fever, irritability, sleep disorders, and failure to thrive develop.

In the suspicion of CDI, the first investigations should foresee the evaluation of serum sodium, osmolality and copeptin levels and urine osmolality [13, 44, 45, 51, 92]. Serum sodium values $>145 \mathrm{mmol} / \mathrm{L}$, serum osmolality $>$ $300 \mathrm{mOsm} / \mathrm{kg}$, and urinary osmolality $<300 \mathrm{mOsm} / \mathrm{kg}$ are indicative of the condition [13,44, 45, 51, 92]. Although the diagnosis of CDI usually requires a water deprivation test and desmopressin (DDAVP) to distinguish CDI from a nephrogenic diabetes insipidus or primary polydipsia, in patients with already diagnosed brain tumors the test is not necessary.

The tumor lesions of the pituitary region that most frequently cause CDI are germinomas, histiocytosis of Langerhans cells, and pinealoma [13]. Neurosurgical lesions of the pituitary stalk and/or of the neurohypophysis are other common causes of acquired CDI, especially when a large tumor in the sellar/suprasellar region is present, as in the case of gangliogliomas or craniopharyngiomas. The development of CDI depends mainly on the neurosurgical approach used, which may be transcranial or transsphenoidal, by the more conservative or rather highly destructive resection amplitude, and by radiotherapy; an approach aimed at saving the hypothalamus seems to have a protective role against the appearance of CDI [95-100].

CDI may be permanent, in case of neuronal loss of AVP-releasing cells, or transient, during neurosurgery or in the subsequent postoperative hours. In $3.4-22.5 \%$ of cases, a "triphasic" pattern may be present: in the first 24-48 $\mathrm{h}$ after the surgery, a transient CDI is present due to edema and pituitary stalk inflammation; subsequently, a phase lasting 1-10 days is characterized by necrosis of the neurohypophyseal cells and consequent release of AVP that causes SIADH; the third phase, which occurs when $>90 \%$ of the neurohypophysial function is lost, is characterized by a permanent CDI and occurs in $75-85 \%$ of patients undergoing sellar/suprasellar neurosurgery $[13,20,46,49]$.

Sodium Disorders in Children with

Pituitary-Suprasellar Tumors
Patients that have experienced the "triphasic" pattern usually develop permanent CDI [95-100]; therefore, neurosurgery is an important step in the treatment of pituitary/suprasellar tumors, and the management of sodium and fluids during the intra- and postoperative phase is quite challenging as both hypernatremia and hyponatremia can occur.

In children with preexisting CDI, d-DDAVP should be administered regularly $6-12 \mathrm{~h}$ before surgery, while in children without preexisting CDI, the measurement of copeptin may point towards the probability of developing CDI [101-104]. To avoid intraoperative water intoxication in patients with CDI, d-DDAVP treatment should be discontinued on the morning of surgery.

Regardless of the previous unbalanced sodium metabolism conditions, during neurosurgery the fluid infusion velocity and concentration are calculated based on serum sodium measurements, urine output, and urine osmolality recorded every hour; when serum sodium is $>147$ $\mathrm{mmol} / \mathrm{L}$ and urine osmolality $<300 \mathrm{mmol} / \mathrm{kg} \mathrm{H}_{2} \mathrm{O}$, and urinary output $>2.5 \mathrm{~mL} / \mathrm{kg} / \mathrm{h}$ for $>2 \mathrm{~h}$, d-DDAVP should be administered intravenously at a dose of $0.5-1 \mu \mathrm{g}$ in children aged $<2$ years or $>2$ years, respectively.

In the $24 \mathrm{~h}$ after surgery, serum sodium and osmolality, urinary osmolality, and output are measured and recorded every $4 \mathrm{~h}$; hydroelectrolytic infusion is calculated as during the neuro-surgery, and intravenous d-DDVAP is administered when necessary, until patients wake up and feel thirsty.

Furthermore, during the intra- and postoperative period of 24-48 h, continuous intravenous hydrocortisone at the dose of stress needs to be administered. When the clinical conditions allow oral ingestion, the hydroelectrolytic infusion must be progressively reduced, the oral fluid intake progressively increased, and any hormone replacement treatments for hypothyroidism, hypocortisolism, and CDI administered again [14].

To detect and treat late hyponatremia or the onset of transient/permanent diabetes insipidus, sodium and water metabolism should be evaluated up to 7-14 days after surgery [13, 20, 44, 45, 51, 92].

The treatment of permanent CDI consists of $d$ DDAVP, which can be administrated orally, sublingually, intranasally, or intravenously $[13,54,61,90,92]$. Actually, the most used way for oral treatment is the sublingual formulation, with an initial dose of $1-4 \mu \mathrm{g} / \mathrm{kg} /$ day in $2-3$ administrations, starting with the lowest dose due to the high renal response, to increase it later, based on the signs of polyuria-polydipsia and serum sodium levels.

Neuroendocrinology 2020;110:161-171 167 


\section{Adipsic CDI}

Adipsic CDI is a particular form of CDI caused by lesions at the level of hypothalamic osmoreceptors, supraoptic/paraventricular or neurohypophyseal regions. Despite the increase in serum osmolality, patients do not feel thirsty and become hypernatremic and dehydrated. This condition is often associated with septo-optic dysplasia or with massive suprasellar cerebral tumors, especially after neurosurgical intervention.

To maintain eunatremia, the standard treatment is represented by d-DDAVP administration and frequent supply of liquids in relation to body weight $(40 \mathrm{~mL} / \mathrm{kg}+$ $300 \mathrm{~mL} / \mathrm{m}^{2}$ perspiration) [13].

\section{Hypernatremia Related to Fluids and Drugs}

To avoid iatrogenic hypernatremia, intravenously administered fluids should always be evaluated for sodium content and infusion rate; hypertonic solutions should be modified in isotonic fluids in relation to the volemic status and sodium correction rate [83-86].

Drug-related hypernatremia can occur when osmotic diuretics are administered. In children with prior CDI diagnosis, in case of persistent hypernatremia, d-DDAVP dosage has to be corrected.

\section{Conclusions}

Disorders of sodium homeostasis are the most frequent electrolytic alterations observed in pediatric cancer patients. Among these conditions, pituitary/suprasellar tumors are at greater risk of developing such complications for lesions in the neuroanatomical circuits of thirst and AVP release.

The maintenance of sodium homeostasis is fundamental not only for neuro-psychomotor development, but also for a better response to treatment and for the disease survival rate. Only a close multidisciplinary cooperation between pediatric oncologists and pediatric endocrinologists allows the achievement of the best management in such severe and complex disorders.

\section{Statement of Ethics}

The authors have no ethical conflicts to declare.

\section{Disclosure Statement}

On behalf of all authors, the corresponding author declares no conflicts of interest.

\section{Funding Sources}

No grant or fellowship has supported this paper.

\section{Author Contributions}

Consent to submit has been explicitly received from all co-authors. All authors whose names appear in the submission have sufficiently contributed to the scientific work and therefore share the collective responsibility and accountability for the results.

\section{References}

1 Gizowski C, Bourque CW. The neural basis of homeostatic and anticipatory thirst. Nat Rev Nephrol. 2018 Jan;14(1):11-25.

2 Zimmerman CA, Leib DE, Knight ZA. Neural circuits underlying thirst and fluid homeostasis. Nat Rev Neurosci. 2017 Aug;18(8):45969.

3 Andersson B. Regulation of water intake. Physiol Rev. 1978 Jul;58(3):582-603.

4 McKinley MJ, Johnson AK. The physiological regulation of thirst and fluid intake. News Physiol Sci. 2004 Feb;19(1):1-6.

5 Verney EB. The antidiuretic hormone and the factors which determine its release. Proc $\mathrm{R}$ Soc Lond B Biol Sci. 1947 Dec;135(878):25106.

6 McKinley MJ, Cairns MJ, Denton DA, Egan G, Mathai ML, Uschakov A, et al. Physiological and pathophysiological influences on thirst. Physiol Behav. 2004 Jul;81(5):795-803.
7 McKinley MJ, Congiu M, Denton DA, Park RG, Penschow J, Simpson JB, et al. The anterior wall of the third cerebral ventricle and homeostatic responses to dehydration. J Physiol (Paris). 1984;79(6):421-7.

8 Hoorn EJ, Geary D, Robb M, Halperin ML, Bohn D. Acute hyponatremia related to intravenous fluid administration in hospitalized children: an observational study. Pediatrics. 2004 May;113(5):1279-84.

9 Ranadive SA, Rosenthal SM. Pediatric disorders of water balance. Endocrinol Metab Clin North Am. 2009 Dec;38(4):663-72.

10 Williams CN, Belzer JS, Riva-Cambrin J, Presson AP, Bratton SL. The incidence of postoperative hyponatremia and associated neurological sequelae in children with intracranial neoplasms. J Neurosurg Pediatr. 2014 Mar;13(3):283-90.
11 Balachandran K, Okines A, Gunapala R, Morganstein D, Popat S. Resolution of severe hyponatraemia is associated with improved survival in patients with cancer. BMC Cancer. 2015 Mar; 15(1):163.

12 Williams CN, Riva-Cambrin J, Presson AP, Bratton SL. Hyponatremia and poor cognitive outcome following pediatric brain tumor surgery. J Neurosurg Pediatr. 2015 May;15(5): 480-7.

13 Edate S, Albanese A. Management of electrolyte and fluid disorders after brain surgery for pituitary/suprasellar tumours. Horm Res Paediatr. 2015;83(5):293-301.

14 Kilday JP, Laughlin S, Urbach S, Bouffet E, Bartels U. Diabetes insipidus in pediatric germinomas of the suprasellar region: characteristic features and significance of the pituitary bright spot. J Neurooncol. 2015 Jan;121(1): $167-75$. 
15 Harrington $\mathrm{MH}$, Casella SJ. Pituitary tumors in childhood. Curr Opin Endocrinol Diabetes Obes. 2012 Feb;19(1):63-7.

16 Zhan R, Xu G, Wiebe TM, Li X. Surgical outcomes of the endoscopic transsphenoidal route to pituitary tumours in paediatric patients $[\{\mathrm{GT}\}] 10$ years of age: 5 years of experience at a single institute. Arch Dis Child. 2015 Aug;100(8):774-8.

17 Unsinn C, Neidert MC, Burkhardt JK, Holzmann D, Grotzer M, Bozinov O. Sellar and parasellar lesions - clinical outcome in 61 children. Clin Neurol Neurosurg. 2014 Aug;123: $102-8$.

18 García-García E, González-Aguilera B, Gros $\mathrm{N}$, Romero-Lluch A, Jiménez-Varo I, Martínez-Ortega AJ, et al. Endocrine diagnosis and treatment of sellar lesions in pediatric age. Endocrinol Nutr. 2014 Aug-Sep;61(7): 359-65.

19 McCrea HJ, George E, Settler A, Schwartz TH, Greenfield JP. Pediatric Suprasellar Tumors. J Child Neurol. 2016 Oct;31(12):1367-76.

20 Matarazzo P, Genitori L, Lala R, Andreo M, Grossetti R, de Sanctis C. Endocrine function and water metabolism in children and adolescents with surgically treated intra/parasellar tumors. J Pediatr Endocrinol Metab. 2004 Nov;17(11):1487-95.

21 Belzer JS, Williams CN, Riva-Cambrin J, Presson AP, Bratton SL. Timing, duration, and severity of hyponatremia following pediatric brain tumor surgery. Pediatr Crit Care Med. 2014 Jun;15(5):456-63.

22 Chemaitilly W, Armstrong GT, Gajjar A, Hudson MM. Hypothalamic-Pituitary Axis Dysfunction in Survivors of Childhood CNS Tumors: Importance of Systematic FollowUp and Early Endocrine Consultation. J Clin Oncol. 2016 Dec;34(36):4315-9.

23 Clement SC, Schouten-van Meeteren AY, Boot AM, Claahsen-van der Grinten HL, Granzen B, Sen Han K, et al. Prevalence and Risk Factors of Early Endocrine Disorders in Childhood Brain Tumor Survivors: A Nationwide, Multicenter Study. J Clin Oncol. 2016 Dec;34(36):4362-70.

24 Mastro-Martínez I, Iglesias-Bouzas MI, Cabeza Martin B, Oñoro-Otero G, Perez-Diaz C, Serrano-Gonzalez A, et al. Early postoperative complications of intracranial tumors in children. Minerva Pediatr. 2017 Oct;69(5): 381-90.

25 Kishimoto K, Kobayashi R, Sano H, Suzuki D, Yasuda K, Kobayashi K. Analysis of Risk Factors for Hyponatremia During or Following Chemotherapy in Children With Cancer: A Hospital-based, Retrospective Cohort Study. J Pediatr Hematol Oncol. 2016 Aug;38(6): 443-8.

26 Rosner MH, Dalkin AC. Electrolyte disorders associated with cancer. Adv Chronic Kidney Dis. 2014 Jan;21(1):7-17.

27 Lameire N, Van Biesen W, Vanholder R. Electrolyte disturbances and acute kidney injury in patients with cancer. Semin Nephrol. 2010 Nov;30(6):534-47.
28 Zieg J. Pathophysiology of Hyponatremia in Children. Front Pediatr. 2017 Oct;5:213.

29 Bockenhauer D, Zieg J. Electrolyte disorders. Clin Perinatol. 2014 Sep;41(3):575-90.

30 Roddy E, Mueller S. Late Effects of Treatment of Pediatric Central Nervous System Tumors. J Child Neurol. 2016 Feb;31(2):237-54.

31 Huynh M, Marcu LG, Giles E, Short M, Matthews D, Bezak E. Current status of proton therapy outcome for paediatric cancers of the central nervous system - Analysis of the published literature. Cancer Treat Rev. 2018 Nov; 70:272-88.

32 Williams CN, Riva-Cambrin J, Bratton SL. Etiology of postoperative hyponatremia following pediatric intracranial tumor surgery. J Neurosurg Pediatr. 2016 Mar;17(3):303-9.

33 Berardi R, Rinaldi S, Caramanti M, Grohè C, Santoni M, Morgese F, et al. Hyponatremia in cancer patients: time for a new approach. Crit Rev Oncol Hematol. 2016 Jun;102:15-25.

34 Albanese A, Hindmarsh P, Stanhope R. Management of hyponatraemia in patients with acute cerebral insults. Arch Dis Child. 2001 Sep;85(3):246-51.

35 Hardesty DA, Kilbaugh TJ, Storm PB. Cerebral salt wasting syndrome in post-operative pediatric brain tumor patients. Neurocrit Care. 2012 Dec;17(3):382-7.

36 González Briceño L, Grill J, Bourdeaut F, Doz F, Beltrand J, Benabbad I, et al. Water and electrolyte disorders at long-term post-treatment follow-up in paediatric patients with suprasellar tumours include unexpected persistent cerebral salt-wasting syndrome. Horm Res Paediatr. 2014;82(6):364-71.

37 Bettinelli A, Longoni L, Tammaro F, Faré PB, Garzoni L, Bianchetti MG. Renal salt-wasting syndrome in children with intracranial disorders. Pediatr Nephrol. 2012 May;27(5):733-9.

38 Tolunay O, Celik T, Celik U, Kömür M, Yağc1-Küpeli B. Cerebral salt wasting in pediatric critical care; not just a neurosurgical disorder anymore. Neuro Endocrinol Lett. 2015 Dec;36(6):578-82.

39 Jiménez R, Casado-Flores J, Nieto M, GarcíaTeresa MA. Cerebral salt wasting syndrome in children with acute central nervous system injury. Pediatr Neurol. 2006 Oct;35(4):261-3.

40 Williams C, Simon TD, Riva-Cambrin J, Bratton SL. Hyponatremia with intracranial malignant tumor resection in children. J Neurosurg Pediatr. 2012 May;9(5):524-9.

41 Hiranrat P, Katavetin P, Supornsilchai V, Wacharasindhu S, Srivuthana S. Water and sodium disorders in children undergoing surgical treatment of brain tumors. J Med Assoc Thai. 2003 Jun;86 Suppl 2:S152-9.

42 Hannon MJ, Finucane FM, Sherlock M, Agha A, Thompson CJ. Clinical review: disorders of water homeostasis in neurosurgical patients. J Clin Endocrinol Metab. 2012 May;97(5): 1423-33.
43 Alharfi IM, Stewart TC, Kelly SH, Morrison GC, Fraser DD. Hypernatremia is associated with increased risk of mortality in pediatric severe traumatic brain injury. J Neurotrauma. 2013 Mar;30(5):361-6.

44 Di Iorgi N, Morana G, Napoli F, Allegri AE, Rossi A, Maghnie M. Management of diabetes insipidus and adipsia in the child. Best Pract Res Clin Endocrinol Metab. 2015 Jun;29(3): 415-36.

45 Jain V, Ravindranath A. Diabetes insipidus in children. J Pediatr Endocrinol Metab. 2016 Jan;29(1):39-45.

46 Kruis RW, Schouten-van Meeteren AY, Finken MJ, Oostdijk W, van Trotsenburg AS, Boot $\mathrm{AM}$, et al. Management and consequences of postoperative fluctuations in plasma sodium concentration after pediatric brain tumor surgery in the sellar region: a national cohort analysis. Pituitary. 2018 Aug;21(4):384-92.

47 Kristof RA, Rother M, Neuloh G, Klingmüller D. Incidence, clinical manifestations, and course of water and electrolyte metabolism disturbances following transsphenoidal pituitary adenoma surgery: a prospective observational study. J Neurosurg. 2009 Sep;111(3): $555-62$.

48 Ciric I, Ragin A, Baumgartner C, Pierce D. Complications of transsphenoidal surgery: results of a national survey, review of the literature, and personal experience. Neurosurgery. $1997 \mathrm{Feb} ; 40(2): 225-36$.

49 Pratheesh R, Swallow DM, Rajaratnam S, Jacob KS, Chacko G, Joseph M, et al. Incidence, predictors and early post-operative course of diabetes insipidus in paediatric craniopharygioma: a comparison with adults. Childs Nerv Syst. 2013 Jun;29(6):941-9.

50 Elliott RE, Jane JA Jr, Wisoff JH. Surgical management of craniopharyngiomas in children: meta-analysis and comparison of transcranial and transsphenoidal approaches. Neurosurgery. 2011 Sep;69(3):630-43.

51 Di Iorgi N, Napoli F, Allegri AE, Olivieri I, Bertelli E, Gallizia A, et al. Diabetes insipidus-diagnosis and management. Horm Res Paediatr. 2012;77(2):69-84.

52 Rose SR, Horne VE, Howell J, Lawson SA, Rutter MM, Trotman GE, et al. Late endocrine effects of childhood cancer. Nat Rev Endocrinol. 2016 Jun;12(6):319-36.

53 Cardoso AP, Dragosavac D, Araújo S, Falcão AL, Terzi RG, Castro M, et al. Syndromes related to sodium and arginine vasopressin alterations in post-operative neurosurgery. Arq Neuropsiquiatr. 2007 Sep;65(3b 3B):745-51.

54 Marques P, Van Huellen H, Fitzpatrick A, Druce M. Late endocrine effects of cancer and cancer therapies in survivors of childhood malignancies. Minerva Endocrinol. 2016 Mar;41(1):78-104.

55 Kaneko K, Noda Y, Yoshimura K. Alternating syndrome of inappropriate secretion of antidiuretic hormone and cerebral salt wasting in an infant with brain tumor. J Pediatr Hematol Oncol. 2014 Apr;36(3):254-5.
Sodium Disorders in Children with Pituitary-Suprasellar Tumors
Neuroendocrinology 2020;110:161-171 DOI: $10.1159 / 000502609$ 
56 Lin JJ, Lin KL, Hsia SH, Wu CT, Wang HS. Combined central diabetes insipidus and cerebral salt wasting syndrome in children. Pediatr Neurol. 2009 Feb;40(2):84-7.

57 Lim YJ, Park EK, Koh HC, Lee YH. Syndrome of inappropriate secretion of antidiuretic hormone as a leading cause of hyponatremia in children who underwent chemotherapy or stem cell transplantation. Pediatr Blood Cancer. 2010 May;54(5):734-7.

58 Prete A, Corsello SM, Salvatori R. Current best practice in the management of patients after pituitary surgery. Ther Adv Endocrinol Metab. 2017 Mar;8(3):33-48.

59 Eisenberg Y, Charles S, Dugas L, Agrawal N. Clinical practice patterns for postoperative water balance after pituitary surgery. Endocr Pract. 2019, Epub ahead of print.

60 Devin JK. Hypopituitarism and central diabetes insipidus: perioperative diagnosis and management. Neurosurg Clin N Am. 2012 Oct;23(4):679-89.

61 Raghunathan V, Dhaliwal MS, Gupta A, Jevalikar G. From cerebral salt wasting to diabetes insipidus with adipsia: case report of a child with craniopharyngioma. J Pediatr Endocrinol Metab. 2015 Mar;28(3-4):323-6.

62 Inskip PD, Veiga LH, Brenner AV, Sigurdson AJ, Ostroumova E, Chow EJ, et al. Hypothyroidism after Radiation Therapy for Childhood Cancer: A Report from the Childhood Cancer Survivor Study. Radiat Res. 2018 Aug; 190(2):117-32.

63 Wei C, Crowne EC. The hypothalamic-pituitary-adrenal axis in childhood cancer survivors. Endocr Relat Cancer. 2018 Oct;25(10): R479-96.

64 Ausiello JC, Bruce JN, Freda PU. Postoperative assessment of the patient after transsphenoidal pituitary surgery. Pituitary. 2008; 11(4):391-401.

65 Liao H, Zhu Z, Rong X, Wang H, Peng Y. Hyponatremia is a potential predictor of progression in radiation-induced brain necrosis: a retrospective study. BMC Neurol. 2018 Aug; 18(1):130.

66 Cuesta M, Thompson CJ. The syndrome of inappropriate antidiuresis (SIAD). Best Pract Res Clin Endocrinol Metab. 2016 Mar;30(2): 175-87.

67 Rivkees SA. Differentiating appropriate antidiuretic hormone secretion, inappropriate antidiuretic hormone secretion and cerebral salt wasting: the common, uncommon, and misnamed. Curr Opin Pediatr. 2008 Aug; 20(4):448-52.

$68 \mathrm{Oh} \mathrm{JY}$, Shin JI. Syndrome of inappropriate antidiuretic hormone secretion and cerebral/renal salt wasting syndrome: similarities and differences. Front Pediatr. 2015 Jan;2:146.

69 Wright WL. Sodium and fluid management in acute brain injury. Curr Neurol Neurosci Rep. 2012 Aug;12(4):466-73.

70 Cuesta M, Garrahy A, Thompson CJ. SIAD: practical recommendations for diagnosis and management. J Endocrinol Invest. 2016 Sep; 39(9):991-1001.
71 Gross P. Clinical management of SIADH. Ther Adv Endocrinol Metab. 2012 Apr;3(2): 61-73.

72 Grant P, Ayuk J, Bouloux PM, Cohen M, Cranston I, Murray RD, et al. The diagnosis and management of inpatient hyponatraemia and SIADH. Eur J Clin Invest. 2015 Aug; 45(8):888-94.

73 Laville M, Burst V, Peri A, Verbalis JG. Hyponatremia secondary to the syndrome of inappropriate secretion of antidiuretic hormone (SIADH): therapeutic decision-making in real-life cases. Clin Kidney J. 2013 Nov;6 Suppl 1:i1-20.

74 Verbalis JG, Greenberg A, Burst V, Haymann JP, Johannsson G, Peri A, et al. Diagnosing and Treating the Syndrome of Inappropriate Antidiuretic Hormone Secretion. Am J Med. 2016 May;129(5):537.e9-23.

75 Winzeler B, Lengsfeld S, Nigro N, Suter-Widmer I, Schütz P, Arici B, et al. Predictors of nonresponse to fluid restriction in hyponatraemia due to the syndrome of inappropriate antidiuresis. J Intern Med. 2016 Dec;280(6): 609-17.

76 Berardi R, Antonuzzo A, Blasi L, Buosi R, Lorusso V, Migliorino MR, et al. Practical issues for the management of hyponatremia in oncology. Endocrine. 2018 Jul;61(1):158-64.

77 Castillo JJ, Vincent M, Justice E. Diagnosis and management of hyponatremia in cancer patients. Oncologist. 2012;17(6):756-65.

78 Marx-Berger D, Milford DV, Bandhakavi M, Van't Hoff W, Kleta R, Dattani M, et al. Tolvaptan is successful in treating inappropriate antidiuretic hormone secretion in infants. Acta Paediatr. 2016 Jul;105(7):e334-7.

79 Tuli G, Tessaris D, Einaudi S, De Sanctis L, Matarazzo P. Tolvaptan utilization in children with chronic hyponatremia due to inappropriate antidiuretic hormone secretion (SI$\mathrm{ADH})$. Three case reports and review of the literature. J Clin Res Pediatr Endocrinol. 2017;9(3):288-92.

80 Higashi K, Murakami T, Ishikawa Y, Itoi T, Ohuchi H, Kodama Y, et al. Efficacy and safety of tolvaptan for pediatric patients with congestive heart failure. Multicenter survey in the working group of the Japanese Society of PEdiatric Circulation and Hemodynamics (JSPECH). Int J Cardiol. 2016 Feb;205:37-42.

81 Regen RB, Gonzalez A, Zawodniak K, Leonard D, Quigley R, Barnes AP, et al. Tolvaptan increases serum sodium in pediatric patients with heart failure. Pediatr Cardiol. 2013 Aug; 34(6):1463-8.

82 Muto S, Kawano H, Higashihara E, Narita I, Ubara Y, Matsuzaki T, et al. The effect of tolvaptan on autosomal dominant polycystic kidney disease patients: a subgroup analysis of the Japanese patient subset from TEMPO 3:4 trial. Clin Exp Nephrol. 2015 Oct;19(5):86777.
83 Ghirardello S, Hopper N, Albanese A, Maghnie M. Diabetes insipidus in craniopharyngioma: postoperative management of water and electrolyte disorders. J Pediatr Endocrinol Metab. 2006 Apr;19 Suppl 1:413-21.

84 Nigro N, Winzeler B, Suter-Widmer I, Schuetz P, Arici B, Bally M, et al. Evaluation of copeptin and commonly used laboratory parameters for the differential diagnosis of profound hyponatraemia in hospitalized patients: 'The Co-MED Study'. Clin Endocrinol (Oxf). 2017 Mar;86(3):456-62.

85 Aylwin S, Burst V, Peri A, Runkle I, Thatcher N. 'Dos and don'ts' in the management of hyponatremia. Curr Med Res Opin. 2015;31(9): 1755-61.

86 Moritz ML, Ayus JC. Prevention of hospitalacquired hyponatremia: a case for using isotonic saline. Pediatrics. 2003 Feb;111(2):22730.

87 Feld LG, Neuspiel DR, Foster BA, Leu MG, Garber MD, Austin K, et al.; Subcommitte on Fluid and Electrolyte Therapy. Clinical Practice Guideline: Maintenance Intravenous Fluids in Children. Pediatrics. 2018 Dec;142(6): e20183083.

88 Choong K, Arora S, Cheng J, Farrokhyar F, Reddy D, Thabane L, et al. Hypotonic versus isotonic maintenance fluids after surgery for children: a randomized controlled trial. Pediatrics. 2011 Nov;128(5):857-66.

89 Ferry RJ Jr, Kesavulu V, Kelly A, Levitt Katz LE, Moshang T Jr. Hyponatremia and polyuria in children with central diabetes insipidus: challenges in diagnosis and management. J Pediatr. 2001 May;138(5):744-7.

90 Finken MJ, Zwaveling-Soonawala N, Walenkamp MJ, Vulsma T, van Trotsenburg AS, Rotteveel J. Frequent occurrence of the triphasic response (diabetes insipidus/hyponatremia/diabetes insipidus) after surgery for craniopharyngioma in childhood. Horm Res Paediatr. 2011;76(1):22-6.

91 Wu X, Zhou X, Gao L, Wu X, Fei L, Mao Y, et al. Diagnosis and Management of Combined Central Diabetes Insipidus and Cerebral Salt Wasting Syndrome After Traumatic Brain Injury. World Neurosurg. 2016 Apr;88:483-7.

92 Dabrowski E, Kadakia R, Zimmerman D. Diabetes insipidus in infants and children. Best Pract Res Clin Endocrinol Metab. 2016 Mar; 30(2):317-28.

93 Matarazzo P, Tuli G, Verna F, Tessaris D, Fiore L, Mussa A, et al. Management of sodium metabolism derangements in children treated for hypothalamic-hypophyseal tumours. J Pediatr Biochem. 2010;1(4):289-96.

94 Elder CJ, Dimitri PJ. Diabetes insipidus and the use of desmopressin in hospitalised children. Arch Dis Child Educ Pract Ed. 2017 Apr;102(2):100-4.

95 Zhang YQ, Ma ZY, Wu ZB, Luo SQ, Wang ZC. Radical resection of 202 pediatric craniopharyngiomas with special reference to the surgical approaches and hypothalamic protection. Pediatr Neurosurg. 2008;44(6):43543. 
96 Hill TK, Baine MJ, Verma V, Alam M, Lyden ER, Lin C, et al. Patterns of Care in Pediatric Craniopharyngioma: Outcomes Following Definitive Radiotherapy. Anticancer Res. 2019 Feb;39(2):803-7.

97 Tan TS, Patel L, Gopal-Kothandapani JS, Ehtisham S, Ikazoboh EC, Hayward R, et al. The neuroendocrine sequelae of paediatric craniopharyngioma: a 40-year meta-data analysis of 185 cases from three UK centres. Eur J Endocrinol. 2017 Mar;176(3):359-69.

98 Bakhsheshian J, Jin DL, Chang KE, Strickland BA, Donoho DA, Cen S, et al. Risk factors associated with the surgical management of craniopharyngiomas in pediatric patients: analysis of 1961 patients from a na- tional registry database. Neurosurg Focus. 2016 Dec;41(6):E8

99 Müller HL. Risk-adapted, long-term management in childhood-onset craniopharyngioma. Pituitary. 2017 Apr;20(2):267-81.

100 Ali ZS, Bailey RL, Daniels LB, Vakhshori V, Lewis DJ, Hossain AT, et al. Comparative effectiveness of treatment options for pediatric craniopharyngiomas. J Neurosurg Pediatr. 2014 Feb;13(2):178-88.

101 Ogawa Y, Niizuma K, Tominaga T. Recovery from diabetes insipidus and preservation of thyroid function after craniopharyngioma removal and pituitary stalk sectioning. Clin Neurol Neurosurg. 2017 Nov;162: 36-40.
102 Winzeler B, Zweifel C, Nigro N, Arici B, Bally $\mathrm{M}$, Schuetz $\mathrm{P}$, et al. Postoperative copeptin concentration predicts diabetes insipidus after pituitary surgery. J Clin Endocrinol Metab. 2015 Jun;100(6):2275-82.

103 Refardt J, Winzeler B, Christ-Crain M. Copeptin and its role in the diagnosis of diabetes insipidus and the syndrome of inappropriate antidiuresis. Clin Endocrinol (Oxf). 2019 Jul;91(1):22-32.

104 Tuli G, Tessaris D, Einaudi S, Matarazzo P, De Sanctis L. Copeptin role in polyuriapolydipsia syndrome differential diagnosis and reference range in paediatric age. Clin Endocrinol (Oxf). 2018 Jun;88(6): 873-9. 